\title{
Social media i nowy marketing w społeczeństwie konsumpcyjnym
}

DOI: 10.19195/2083-7763.9.12

\section{Wstęp}

Wśród teorii socjologicznych można znaleźć co najmniej dwa wyjaśnienia powstania społeczeństwa konsumpcyjnego. Pierwsze z nich odwołuje się do ekonomii, upatrując we wzroście wydajności produkcji i bogaceniu się społeczeństwa przyczyn rewolucji konsumpcyjnej, drugie zaś nawiązuje do kultury, traktując zmianę praktyk społecznych i wzorów konsumpcji jako wynik zmian w zakresie zwyczajowych norm społecznych.

W książce Wolność z 1988 roku Zygmunt Bauman przeciwstawia społeczeństwo konsumpcyjne wcześniejszej formie - społeczeństwu producentów ${ }^{1}$. O ile w społeczeństwie producentów osią życia była praca, która determinowała status, miejsce w hierarchii, była wyznacznikiem tożsamości społecznej i samooceny, o tyle w społeczeństwie konsumpcyjnym analogiczną rolę odgrywa konsumpcja. „Konsumować więc to tyle, co inwestować we własne członkostwo w społeczeństwie"2. W społeczeństwie konsumpcyjnym, w przeciwieństwie do społeczeństwa producentów, regulacja normatywna, jako narzędzie dyscyplinujące, traci na znaczeniu. Im ściślejsze normy, tym większe ograniczenie wolności, a zatem odrzucenie regulacji normatywnych staje się siłą napędową wolnego rynku i sprzyja pojawieniu się społeczeństwa konsumpcyjnego ${ }^{3}$. Jednocześnie wolność i obfitość wyboru staje

${ }^{1}$ Ł. Iwasiński, Społeczeństwo konsumpcyjne w ujęciu Zygmunta Baumana, „Kultura i Społeczeństwo" 2015, nr 4.

${ }^{2}$ Z Baumann, Konsumowanie życia, Kraków 2009, s. 65, cyt. za: Ł. Iwasiński, op. cit., s. 5.

${ }^{3}$ Ibidem. 
się głównym czynnikiem stratyfikującym ${ }^{4}$, nierówność dochodów jest bowiem jedną z różnic klasowych i kulturowych, które nakładają się na różnice w sposobie ubierania, wykształceniu, poczuciu własnej wartości czy tożsamości ${ }^{5}$.

Dominujący od kilkunastu lat $\mathrm{w}$ naukach społecznych paradygmat widzi w konsumpcji narzędzie refleksyjnego kształtowania tożsamości konsumenta ${ }^{6}$. Część socjologów jednak doszukuje się w jednostkach tożsamości sformatowanej przez marketing. Niewątpliwie autorce niniejszego opracowania bliższe jest to drugie stanowisko, przy czym upatruje w tym pewnego rodzaju determinizm technologiczny. Współczesny konsument, zanurzając się w świecie nowych technologii, który jest jego wyborem, jednocześnie poddaje się stechnicyzowanym środkom marketingowym, możliwym za sprawą tychże technologii. Autorka na podstawie danych zastanych stawia tezę, że rozbuchany indywidualizm, wzmocniony między innymi przez nowe media, został z powodzeniem wykorzystany przez marketingowców do sprzedaży zestandaryzowanych produktów.

Celem artykułu, wychodzącego od koncepcji społeczeństwa konsumpcyjnego, jest przedstawienie roli nowych mediów w życiu konsumentów. Analiza danych w zakresie użytkowania technologii i nowych mediów pokazuje tempo zastępowania jednych technologii — aplikacji - nowszymi. Wyraźnie zaznaczają się różnice międzypokoleniowe, a kapitał kulturowy i ekonomiczny wpływa na zróżnicowanie w zakresie posiadania i użytkowania nowych mediów. Z jednej strony użytkowanie nowych technologii pozwala jednostkom kształtować niepowtarzalną tożsamość, z drugiej zaś te same technologie z powodzeniem są wykorzystywane przez specjalistów marketingu. Rynek korzysta $\mathrm{z}$ technik manipulacyjnych, oddziałując na masy i jednostki ${ }^{7}$. To głównie młodzi ludzie są atrakcyjnym targetem ze względu na ich zanurzenie w technologii i pogoń za nowinkami, ale marketingowcy dostrzegają też zagrożenia swojej skuteczności. Im więcej użytkowników social media, im więcej treści, tym trudniej zarządzać wizerunkiem i gasić pożary. Problem stanowią też polscy konsumenci nowych mediów, stawiający czynny opór nachalnej reklamie.

\section{Od rewolucji konsumpcji do kultury indywidualizmu. Kontekst teoretyczny}

W społeczeństwie konsumpcyjnym wybór jest cnotą, a samostanowienie autokreacja jego esencją. W epoce późnej nowoczesności indywidualizm daje

${ }^{4}$ Z. Baumann, Praca, konsumpcjonizm i nowi ubodzy, Kraków 2006, s. 71, cyt. za: Ł. Iwasiński, op. cit. s. 6.

${ }^{5}$ R. Wilkinson, K. Pickett, Duch równości. Tam gdzie panuje równość, wszystkim żyje się lepiej, przeł. P. Listwan, Warszawa 2011.

${ }^{6}$ Ł. Iwasiński, Konsumpcja jako budowanie tożsamości, „Studia Socjologiczne” 2015, nr 4 (219), s. $159-180$.

${ }^{7}$ K. Pasikowski, Konsumpcja: w pogoni za wolnością?, [w:] Co nas wyzwala, co nas zniewala? Młodzi o wolności, red. A. Kampka, K. Masłowska A. Pawłowska, Warszawa 2018. 
jednostce możliwość kreacji na niespotykaną dotąd skalę ${ }^{8}$ Genezy społeczeństwa konsumpcyjnego upatruje się w załamaniu światowego porządku gospodarczego w latach 70. XX wieku. Jedną z konsekwencji było ograniczanie pracy w przemyśle na rzecz usług, przesunięcie z produkcji na konsumpcję. Należy podkreślić, że choć ten nowy typ organizacji społecznej badacze nazwali społeczeństwem konsumpcyjnym, to konsumpcja masowa była ważnym elementem także w społeczeństwie przemysłowym ${ }^{9}$. Gwałtowny wzrost nakładów na dobra produkowane masowo w XVIII wieku nazwano rewolucją konsumpcyjną ${ }^{10}$. Według Arjuna Appaduraia rewolucja konsumpcyjna nie wyraża się jednak w kategoriach ekonomicznych, lecz praktykach społecznych, dlatego początku rewolucji konsumpcyjnej upatruje on już w XV wieku. Appadurai wyróżnia trzy podstawowe wzory społecznie zorganizowanych form konsumpcji, są to: zakaz, norma regulatywna i moda. Pierwszy $\mathrm{z}$ nich charakteryzował proste społeczności zorientowane rytualnie, w których porządek świata sprowadzał się do listy rzeczy, których robić nie wolno. Norma regulatywna charakteryzuje epokę feudalną, w której konsumpcja określonych dóbr wyznacza pozycje w hierarchii społecznej, wykluczając naśladownictwo osób zajmujących inne pozycje w strukturze stratyfikacyjnej. Wzór ten przekształca się w modę, praktykę charakterystyczną dla nowoczesnych społeczeństw kapitalistycznych ${ }^{11}$. Moda, podobnie jak obyczaj, jest formą związku społecznego opartego na naśladowaniu, ale obyczaj to naśladowanie tego, co było, moda zaś jest naśladowaniem tego, co tu i teraz ${ }^{12}$.

Moda wzmacnia wolność jednostki, która jednocześnie dąży do wyróżniania się i bycia kimś wyjątkowym ${ }^{13}$. Prawem jednostki jest możliwość wyboru sposobu życia poprzez dobieranie elementów z dostępnego zbioru, „człowiek obserwując wokół siebie rozmaite zewnętrzne wzory dotyczące różnych elementów życia, wybiera wśród nich, indywidualnie je z sobą zestawiając, nieustannie wymieniając różne elementy, gdyż jest wrażliwy na ich nowość i zmienność" ${ }^{14}$.

Wybór konstytuuje kulturę indywidualizmu. Jak stwierdza Małgorzata Jacyno: „W wolności rozumianej jako wybieranie realizuje się bowiem poczucie podmio-

${ }^{8}$ A. Cudowska, Wspólnota w kulturze indywidualizmu, [w:] Wspólnoty z perspektywy edukacji międzykulturowej, red. J. Nikitorowicz, J. Muszyńska, M. Sobecki, Białystok 2009.

${ }_{9}$ J. Zalewska, Rewolucja konsumpcyjna: od gospodarki naturalnej do społeczeństwa mody, [w:] Krótkie wykłady z socjologii. Kategorie, problemy, subdyscypliny, red. E. Tarkowska, A. Firkowska-Mankiewicz, T. Kanasz, Warszawa 2013, s. 139-151.

${ }^{10}$ N. McKendrick, J. Brewer, J.H. Plumb, The Birth of a Consumer Society: The Commercialization of Eighteenth-Century England, Bloomington 1982.

11 A. Appadurai, Nowoczesność bez granic. Kulturowe wymiary globalizacji, przeł. Z. Pucek, Kraków 2005.

12 G. Lipovetsky, L'Empire de léphémère: la mode et son destin dans les sociétés modernes, Pronceton-Oxford 1987, s. 226-229, cyt. za: T. Szlendak, K. Pietrowicz, Moda, wolność i kultura konsumpcji, [w:] Rozkoszna zaraza. O rzadach mody i kulturze konsumpcji, red. T. Szlendak, K. Piotrowicz, Wrocław 2007.

${ }^{13}$ T. Szlendak, K. Pietrowicz, Moda, wolność i kultura konsumpcji, [w:] Rozkoszna zaraza...

${ }^{14}$ G. Lipovetsky, L'Empire..., cyt. za: J. Zalewska, op. cit., s. 150. 
towości jednostek"15. Największy wpływ na kształtowanie się indywidualisty mają media. W literaturze socjologicznej domyślnie traktuje się telewizję jako medium kultury indywidualizmu ${ }^{16}$. Media, dostarczając konsumentom różnych schematów zachowań, z jednej strony prowadzą do społecznego nasycenia ${ }^{17}$, a z drugiej wzmagają refleksyjność ${ }^{18}$ i wymuszają wybór schematów zachowań budujących podmiotowość jednostki ${ }^{19}$. Jednak dopiero upowszechnienie się Web 2.0, czyli „systemu komunikacji charakteryzującego się autonomią, horyzontalnym tworzeniem sieci, interaktywnością i możliwością ponownego łączenia treści zgodnie z inicjatywą jednostki i jego/jej sieci”20, wzmocniło „hegemonię ekspresyjnego, usieciowionego Ja"21.

\section{Użytkownicy nowych mediów}

Badania Pew Research Center z 2018 roku ${ }^{22}$ dotyczące amerykańskich dorosłych świadczą o tym, że krajobraz mediów społecznościowych jest zdefiniowany przez połączenie dawnych i nowych trendów. Większość amerykańskich dorosłych korzysta z Facebooka i YouTube’a, ale młodsi Amerykanie (zwłaszcza w wieku od 18 do 24 lat) wyróżniają się większą różnorodnością i częstością korzystania z platform. Około 78\% badanych w wieku 18-24 lat używa Snapchata, a $71 \%$ odwiedza platformę kilka razy dziennie. Podobnie 71\% Amerykanów w tej grupie wiekowej korzysta $\mathrm{z}$ Instagrama, a blisko połowa to użytkownicy Twittera. YouTube jest obecnie używany przez prawie trzy czwarte dorosłych w USA i $94 \%$ osób w wieku od 18 do 24 lat.

Istnieją znaczne różnice $\mathrm{w}$ korzystaniu $\mathrm{z}$ mediów społecznościowych w poszczególnych grupach wiekowych. Około $88 \%$ osób w wieku od 18 do 29 lat

${ }^{15}$ M. Jacyno, Kultura indywidualizmu, Warszawa 2007.

16 Zob. J.B. Thompson, Media i nowoczesność: społeczna teoria mediów, przeł. I. Mielnik, Wrocław 2001; A. Giddens, Nowoczesność i tożsamość. „Ja” i społeczeństwo w epoce późnej nowoczesności, przeł. A. Szulżycka, Warszawa 2002; M. Halawa, Życie codzienne z telewizorem. Z badań terenowych, Warszawa 2006, za: M. Halawa, Facebook - platforma algorytmicznej towarzyskości i technologia siebie, „Kultura i Społeczeństwo” 2013, nr 4, doi:10.2478/kultura-2014-0007.

17 G. Kenneth, Nasycone Ja. Dylematy tożsamości w życiu współczesnym, przeł. M. Marody, Warszawa 2009.

18 J.C. Kaufmann, Kiedy ja jest innym. Dlaczego i jak coś się w nas zmienia, przeł. A. Kapciak, Warszawa 2013.

${ }^{19}$ J. Zalewska, Wplyw mody na kształtowanie się emocjonalnego podmiotu, [w:] Od obyczaju do mody: Przemiany życia codziennego, red. J. Zalewska, M. Cobel-Tokarska, Warszawa 2014, s. 419.

${ }^{20}$ M. Castells, Władza komunikacji, przeł. J. Jedliński, P. Tomanek, Warszawa 2013, s. 133.

${ }^{21}$ M. Halawa, Facebook..., s. 120.

22 A. Smith, M. Anderson, A majority of Americans use Facebook and YouTube, but young adults are especially heavy users of Snapchat and Instagram, http://www.pewinternet.org/2018/03/01/ social-media-use-in-2018/ (dostęp: 30.10.2018). 
wskazuje, że korzysta z dowolnej formy mediów społecznościowych. Udział ten spada do $78 \%$ wśród osób w wieku od 30 do 49 lat, do 64\% wśród osób w wieku od 50 do 64 lat i do 37\% wśród Amerykanów w wieku 65 lat i starszych.

Młodzi w wieku od 18 do 24 lat są znacznie bardziej skłonni do korzystania $\mathrm{z}$ takich platform, jak Snapchat (78\%), Instagram i Twitter, wśród młodych dorosłych w wieku 25-29 lat użytkowników Snapchata jest już tylko 54\%.

Z wyjątkiem osób w wieku 65 lat i starszych Facebook jest używany przez większość Amerykanów w szerokim zakresie grup demograficznych. Ale inne platformy odwołują się mocniej do pewnych podgrup populacji. Podczas gdy ogólny udział Amerykanów używających Snapchata jest mniejszy niż w wypadku Facebooka, podobny odsetek użytkowników Snapchata (49\%) twierdzi, że korzysta z platformy kilka razy dziennie. Ogólnie rzecz biorąc, większość użytkowników Snapchata (63\%) i Instagrama (60\%) wskazuje, że codziennie odwiedza te platformy. W wypadku Instagrama był to wzrost o 9 punktów procentowych w porównaniu z rokiem 2016.

Około 82\% użytkowników Snapchata w wieku od 18 do 24 lat twierdzi, że codziennie korzysta z platformy, a $71 \%$ z nich używa jej kilka razy dziennie. Podobnie $81 \%$ użytkowników Instagrama w tej grupie wiekowej codziennie odwiedza platformę, a $55 \%$ z nich deklaruje, że robi to kilka razy dziennie ${ }^{23}$.

W Polsce trendy są bardzo podobne. Korzystanie z sieci jest zróżnicowane ze względu na wiek. Im młodsi użytkownicy, tym częściej korzystają z internetu, w grupie wiekowej 14-35 lat z internetu korzystają prawie wszyscy. O ile najstarsi internauci szukają informacji na stronach czasopism, młodsi nie mają takiej potrzeby. Młode pokolenie jest zanurzone $\mathrm{w}$ świecie informacji, a wiedzę o świecie czerpie z mediów społecznościowych. W 2017 roku 14 mln było aktywnymi użytkownikami stron social media ${ }^{24}$. Z raportu przygotowanego przez Universal McCann wynika, że $42 \%$ badanych z Polski traktuje media społecznościowe jako nieodłączną część życia społecznego. Wśród użytkowników w wieku 25-34 wskaźnik ten wynosi prawie $50 \%$, a u osób należących do grupy wiekowej $16-24$ przekracza $50 \%{ }^{25}$. Jednocześnie social media to nie tylko medium komunikacyjne czy okno na świat. Badani przypisują technologii ludzkie cechy — Instagram „rozumie moje potrzeby”, „jest świetnym miejscem dla takich osób jak ja” oraz „jest innowacyjny, ekscytujący, otwarty na zmianę”. O Snapchacie natomiast więcej „mówi się w gronie znajomych”, a sam serwis postrzegany jest jako „zabawne, pozytywne miejsce”26.

${ }^{23}$ Ibidem.

${ }^{24}$ T. Bodył, Z Internetu korzystamy prawie wszyscy. W jaki sposób Polacy korzystają z sieci i co robiq źle?, https://tech.wp.pl/z-internetu-korzystamy-prawie-wszyscy-w-jaki-sposob-polacy-korzystaja-z-sieci-i-co-robia-zle-6197262071432833a (dostęp: 30.10.2018).

${ }^{25}$ Polacy w mediach społecznościowych najczęściej oglądaja wideo i podglądają znajomych, http:// www.proto.pl/aktualnosci/polacy-w-mediach-spolecznosciowych-najczesciej-ogladaja-wideo-i-podgladaja-znajomych (dostęp: 15.11.2018).

${ }^{26}$ Raport Wave, Znaczenie momentów, http://www.universalmccann.pl/news/68/114/Wave-9Polak-zapatrzony-w-Facebooka (dostęp: 17.11.2018). 
Dzisiaj nie wystarczy już korzystanie z sieci, o wiele ważniejsze jest bycie cały czas online. To umożliwia technologia mobilna. Z danych GUS wynika, że w 2017 roku prawie $60 \%$ Polaków miało smartfon. Ale już w grupie młodych 16-24 lata odsetek wynosił $91 \%{ }^{27}$. Z badań Pew Researchr Center z roku 2018 wynika, że posiadaczami smartfonów jest 77\% Amerykanów, ale już 94\% młodych osób w wieku od 18 do 29 lat. Jednocześnie posiadanie smartfonu jest pozytywnie skorelowane $\mathrm{z}$ wykształceniem, dochodami i mieszkaniem w mieście, we wszystkich tych kategoriach właściciele smartfonów stanowią ponad $90 \%{ }^{28}$.

Marek Krajewski, mówiąc o znaczeniu telefonów dla młodych ludzi, wskazuje, że są to urządzenia, które zarówno łączą, jak i dzielą.

chociaż wszyscy jesteśmy wpięci do sieci i równie zależni od urządzeń komunikacyjnych, to jednocześnie tworzymy osobne ludzko-przedmiotowe zbiorowości i to one generują również społeczne różnice, $\mathrm{w}$ tym te międzypokoleniowe. Te ostatnie są wzmacniane nie tylko poprzez opisywaną tu specyfikę kodów ograniczonych, ale też przez unikalność, wykorzystywanych jako zapośredniczenia, urządzeń, przez ich personalizowanie i idiosynkratyczny sposób ich wykorzystywania. Nie chodzi tu przy tym o to, że młodzi ludzie nie używają pewnych typów telefonów komórkowych, traktując je jako obciachowe, czy też o to, że fetyszyzują oni niektóre z urządzeń, uznając je za ekskluzywnie własne, „młodzieżowe”, ale też o to, że wydają się kategorią, w której szczególnie częste jest indywidualizowanie tego rodzaju urządzeń i traktowanie tego procesu jako równoznacznego $\mathrm{z}$ wyodrębnieniem się jednostki jako kogoś unikalnego ${ }^{29}$.

Marki technologiczne mają dużą wartość symboliczną. W 2014 roku wśród dziesięciu najważniejszych marek znalazły się kolejno: Samsung, Google, YouTube, Facebook, Apple, Twitter, Visa, Instagram i Sony. Aż 60\% badanych w grupie wiekowej 16-34 lat zaznaczyło, że czuje się dobrze, gdy widzi kogoś korzystającego z tej samej marki co oni. Wśród osób w wieku powyżej 55 lat odsetek zadowolonych z tego, że ktoś używa tej samej marki, wyniósł $38 \%{ }^{30}$.

\section{Nowy marketing}

Jak dowodzą w swoich książkach Heath i Potter ${ }^{31}$ oraz Lash i Lury ${ }^{32}$, dzisiejsza konsumpcja, odwołując się do różnicy, kreatywności i stylu życia, dostarcza

${ }^{27}$ Miliony Polaków nie mają $w$ domu internetu. I żyją, „Forbes”, https://www.forbes.pl/gospodarka/spoleczenstwo-informacyjne-ilu-polakow-ma-smartfony-i-dostep-do-internetu/9139ph4 (dostęp: 15.11.2018).

${ }^{28}$ Mobile Fact Sheet, http://www.pewinternet.org/fact-sheet/mobile/ (dostęp: 15.11.2018).

${ }^{29}$ M. Krajewski, Przeterminowanie, [w:] Młodzi i media nowe media a uczestnictwo w kulturze. Raport Centrum Badań nad Kultura Popularna SWPS, Warszawa 2010.

${ }^{30}$ I. Kołacz, Dla młodych ludzi licza się przede wszystkim marki związane zcyfrowa technologia, https:// www.press.pl/tresc/37540,dla-mlodych-ludzi-licza-sie-przede-wszystkim-marki-zwiazane-z-cyfrowa-technologia (dostęp: 15.11.2018).

31 J. Heath, A. Potter, Nation of Rebel. Why Counterculture Became Consumer Culture, New York 2004.

32 S. Lash, C. Lury, Global Culture Industry: The Mediation of Things, Cambridge 2007. 
nieustannych nowości w miejsce rzeczy coraz szybciej ten walor tracących ${ }^{33}$. Z badań przeprowadzonych w 2010 roku wynika, że $85 \%$ badanych uważa się za osoby myślące niezależnie, które jako pierwsze próbują nowych rzeczy (41\%). Jednocześnie ponad połowa (54\%) postrzega siebie jako ekspertów, którzy często proszeni są o rady w wielu dziedzinach ${ }^{34}$.

W kulturę konsumpcji wpisane są sposoby postrzegania rzeczywistości, wartościowania oraz działania. Towary i usługi mają wartość symboliczną, która nadaje z kolei wartość ich nosicielom, rozumianą i odczytywaną przez społeczeństwo $^{35}$. Wojciech Burszta uważa, że

nacisk kładziony na jednostkę i jej samookreślenie względem rynkowej oferty skutkuje przekonaniem, że konsument jest indywidualnością, która może określić własną tożsamość przede wszystkim za pomocą rzeczy, które zdecyduje się kupić i manifestować ich posiadanie ${ }^{36}$.

Ale nacisk kładziony na jednostkę to jakaś forma zewnętrznego wobec jednostki przymusu. Alan Aldridge twierdzi, że to nie potrzeby konsumentów napędzają rynek, ale potrzeby narzucone przez tych, którzy mają zamiar je zaspokoić, co oznacza, że korporacje za pomocą „manipulacyjnego aparatu perswazji” nakłaniają konsumentów do potrzebowania tego, co zaraz będą mogli kupić ${ }^{37}$. Podobnie argumentuje Krystyna Romaniszyn, nazywając specjalistów do spraw reklamy i marketingu „promotorami hedonistycznego etosu konsumpcji”38.

Tyle, że od ponad dekady żyjemy w świecie komunikacji 2.0, a od kilku lat w rzeczywistości zdominowanej przez social media. W dobie mediów społecznościowych nie sprzedaje się towaru, tylko markę. Marka stała się narzędziem, dzięki któremu producent może skutecznie zakomunikować różnicę, a klientom pozwala tę różnicę wyłowić i właściwie zinterpretować ${ }^{39}$. Alicja Cybulska z Havas Media Group przywołuje badania, z których wynika, że 75\% respondentów zgadza się $\mathrm{z}$ tezą, że marki powinny odgrywać rolę w procesie poprawy jakości naszego życia. W krajach rozwiniętych 8 na 10 marek o najwyższym znaczeniu dla klientów to marki technologiczne. Innowacje technologiczne najbardziej kojarzą się

33 W.J. Burszta, Styl życia - kontrkultura - gadżet, [w:]Co nas łączy, co nas dzieli?, red. J. Mucha, E. Narkiewicz-Niedbalec, M. Zielińska, Zielona Góra 2008.

${ }^{34}$ Badanie KNOW: Konsument w mediach społecznościowych zostało przeprowadzone przez IMAS International sp. z o.o. we Wrocławiu na zlecenie Euro RSCG Sensors. Miało formę ankiety internetowej i objęto nią osoby w wieku 18-64 zarejestrowane w internetowym panelu badawczym IMAS Online. Respondenci ( $\mathrm{n}=538)$ to osoby korzystające $\mathrm{z}$ co najmniej dwóch serwisów społecznościowych raz w tygodniu, https://blog.kurasinski.com/2010/03/raport-media-spolecznosciowe/.

${ }^{35}$ K. Pasikowski, Konsumpcja: w pogoni za wolnością?, [w:] Co nas wyzwala...

36 Ibidem, s. 392.

37 A. Aldridge, Konsumpcja, przeł. M. Żakowski, Warszawa 2006, s. 26.

${ }^{38}$ K. Romaniszyn, O sile konsumpcjonizmu, [w:] Nowa droga do zniewolenia? O życiu w społeczeństwie konsumpcyjnym, red. K. Romaniszyn, Kraków 2011, s. 15-50.

${ }^{39}$ M. Staniszewski, Narzędzia: zarządzanie znaczeniem marki, „Marketing w praktyce” 2008, $\mathrm{nr}$ 8, http://marketing.org.pl/archiwum/index.php/go=2/act=2/aid=m4895cf888d7cf. (dostęp: 17.11.2018). 
z poprawą jakości życia ${ }^{40}$. Dziś marka, choć niematerialna, stała się narzędziem, które kojarzyć się ma konsumentowi z konkretnym emocjami.

W społeczeństwie konsumpcyjnym marka stała się swoistym kulturowym fetyszem. Marketing nadał jej sens symboliczny - związany ze statusem. Niejednokrotnie marka okazuje się istotniejsza od samego opatrzonego nią produktu, toteż konsument płaci przede wszystkim za wykreowany dzięki marketingowi znak ${ }^{41}$.

Nastolatki i młodzi dorośli są celem marketingowców ze względu na ich siłę nabywczą. Poznanie ich preferencji w zakresie odnoszenia się do marki i lojalności wobec niej są celem specjalistów od marketingu. Marketingowcy wychodzą z założenia, że nabywcy wolą proste wybory i marka im w tym pomaga. Aby zrozumieć potrzeby swoich klientów, a przez to zwiększyć wybieralność danych produktów, marki wykorzystują technologię, a zdobytą wiedzę wykorzystują do stworzenia ekosystemu usług spełniających wiele potrzeb ${ }^{42}$. Marki mają do odegrania rolę doradcy w ustalaniu tożsamości i poprawie statusu społecznego. 45\% najmłodszych respondentów (w wieku 16-34 lat) znacznie częściej niż starsze pokolenia twierdziło, że marki są „istotną" częścią ich życia ${ }^{43}$.

O przyłączeniu się kiedykolwiek do społeczności marki wspomina $40 \%$ badanych Polaków ${ }^{44}$. Z poradnika dla marketerów możemy dowiedzieć się, że konsumenci w zależności od sytuacji, wieku i stanu posiadania będą poszukiwać różnych partnerów do realizacji własnych potrzeb. „Zawsze jednak mają bardzo konkretne oczekiwania, wiedzą, czego chcą i co powinieneś im zaoferować"45. W technologicznym ekosystemie skuteczny marketer powinien mówić do konsumenta nie tylko zrozumiałym językiem w sensie werbalnym, lecz także takim, w którym klient myśli i czuje.

Media społecznościowe są komfortową przestrzenią i idealnym narzędziem komunikacyjnym dla branży odzieżowej i kosmetycznej:

Wpisana w te dziedziny wizualność jest kluczowa dla kultury obrazkowej, w jakiej funkcjonujemy i na której bazują serwisy takie, jak Facebook, Instagram czy Snapchat. Moda ma charakter

${ }^{40}$ Wywiad z Alicją Cybulską (Havas Media Group) dla „Nowy Marketing”, https://nowymarketing.pl/a/13171,alicja-cybulska-havas-media-group-dla-zaufania-klienta-wazne-jest-to-czy-marka-jest-liderem-na-rynku (dostęp: 30.10.2018).

${ }^{41}$ Ł. Iwasiński, Narodziny społeczeństwa konsumpcyjnego, „Sensus Historiae” 18, 2015, nr 1, s. 142.

${ }^{42}$ Ł. Ostruszka, Technologia napędza wartość marki, https://www.pb.pl/technologia-napedza-watosc-marki-931535 (dostęp: 15.11.2018).

${ }^{43}$ I. Kołacz, Dla młodych ludzi licza się przede wszystkim marki związane z cyfrowa technologia, https://www.press.pl/tresc/37540,dla-mlodych-ludzi-licza-sie-przede-wszystkim-marki-zwiazane-z-cyfrowa-technologia (dostęp: 15.11.2018).

${ }^{44}$ Raport Wave.

${ }^{45}$ M. Staniszewski, op. cit. 
nie tylko handlowy, sprzedażowy, ale i medialny, widowiskowy — i z tego korzystają specjaliści ds. social media działający w e-commerce ${ }^{46}$.

Polakom nie przeszkadza obecność marek w social media, aż 72\% deklarowało, że za ich pomocą wchodzi z markami w interakcje. Podobny odsetek badanych dzielił się doświadczeniami z markami i produktami, ale 43\% krytykowało anonimowo w mediach społecznościowych firmy lub marki. jest To istotny problem dla specjalistów od zarządzania wizerunkiem marki. Do interakcji z markami, poza sympatią, zachęcają konkursy i promocje, specjalne oferty, a także aktualności dotyczące firmy czy marki ${ }^{47}$.

Obok marketingu opartego na marce ważnym narzędziem jest marketing oparty na influencerach. Narzędzie to opiera się na współdziałaniu firmy z blogerami, vlogerami, celebrytami, którzy stają się ambasadorami marek i liderami opinii.

Angażowanie znanych i lubianych celebrytów w kampanie reklamowe i wizerunkowe to inwestycja, która się opłaca. Przy takiej kooperacji zwiększa się widoczność marki w sieci, poszerza znajomość i rozpoznawalność brandu, ponieważ informacja o produkcie/usłudze trafia do wszystkich obserwatorów ambasadora. Marka w pakiecie z influencerem „otrzymuje” jego odbiorców, czyli szansę na pozyskanie nowych klientów i wzrost sprzedaży ${ }^{48}$.

Marketing oparty na influencerach jest odpowiedzią na sytuację, w której

w świecie zdominowanym przez treści generowane przez użytkowników sieci społecznościowych nie stosuje się konwencjonalnych strategii reklamowych, skierowanych do masowej widowni. W społecznych środowiskach internetowych zamieszkanych przez „przyjaciół” użytkownicy nie tolerują działalności komercyjnej ${ }^{49}$.

Ten rodzaj relacji opiera się na zaufaniu klienta do kogoś, z kim się utożsamia. Klient wierzy, że bloger jest uczciwy i nie oszuka go, w przeciwieństwie do tradycyjnej reklamy.

Chociaż usieciowienie i zanurzenie młodych konsumentów w nowych mediach daje marketingowcom wiele okazji do skuteczniejszego, spersonalizowanego dotarcia z przekazem, to jednocześnie specjaliści od marketingu zdają sobie sprawę z konieczności ciągłej ewolucji narzędzi. Ta konieczność pozostaje w związku z tempem zmian technologicznych, a co za tym idzie - szybko zmieniającymi się zachowaniami konsumentów. Presja dotycząca innowacyjności w takim samym stopniu dotyka zarówno młodych dorosłych, jak i działy marketingu ${ }^{50}$.

${ }^{46}$ A. Szymanek, Branża mody a trendy w mediach społecznościowych, http://fashionweare.com/ rynek_mody/bran\%C5\%BCa-mody-a-trendy-w-mediach-spo\%C5\%82eczno\%C5\%9Bciowych-373 (dostęp: 15.11.2018).

47 Badanie KNOW...

48 A. Szymanek, op. cit.

${ }^{49}$ I. Wolska-Zogata, Prasa informacyjna w ekosystemie nowych mediów, „Media - Kultura Komunikacja Społeczna" 14, 2018, nr 3, s. 33.

50 A. Mardosz-Grabowska, Czego nie umieja marketerzy? 5 trendów w marketingu i 15 kluczowych potrzeb szkoleniowych, https://nowymarketing.pl/a/19016,czego-nie-umieja-marketerzy-5-trendow-w- marketingu-i-15-kluczowych-potrzeb-szkoleniowych (dostęp: 18.11.2018). 
Zauważalny trend związany z „wylogowywaniem” się konsumentów z mediów społecznościowych czy komercjalizacja treści na kanałach społecznościowych to tylko zwiastun nadchodzących zmian ${ }^{51}$. Interesujących danych dostarczają badania dotyczące blokowania reklam w internecie.

Według raportu OnAudience.com internauci w Polsce są na szczycie listy popularności wtyczek blokujących reklamy w sieci. Korzystanie z adblocków w naszym kraju wzrosło do 46 procent (8-procentowy wzrost rok do roku). Wartość zablokowanych odsłon w 2017 roku osiągnie 42 miliardy dolarów. Prawie połowa internautów nie widzi więc reklam typu display ${ }^{52}$.

\section{Podsumowanie}

Nowe technologie, i co za tym idzie - globalizacja, mają w społeczeństwie ponowoczesnym duży wpływ na kształtowanie się konsumenta. Pogodzenie masowej konsumpcji (przy standaryzacji, jaką za sobą pociągała) z rozbuchanym indywidualizmem należy do największych osiągnięć cywilizacji zachodniej ${ }^{53}$. Zasadą współczesnej kultury jest ekspresja, normami zachowań - gusta i preferencje. Wybory podporządkowane ekspresyjności, a nie instrumentalności, zorientowane są na teraźniejszość, a nie na przyszłość ${ }^{54}$.

Permanentna zmiana, która napędza zachowania konsumentów, dotyka także marketerów. Specjaliści od sprzedaży odpowiadają na zmiany technologiczne i zmiany w zakresie ich użytkowania, i czują presję przewidywania trendów. Najatrakcyjniejszą kategorią konsumentów są młodzi dorośli i to do nich marketingowcy szukają kanałów dostępu. Jednym z narzędzi jest kreowanie świata przeżyć związanego z marką, a nie z konkretnym produktem. Marki są bowiem dzisiaj nie tylko nazwami produktów kupowanych przez konsumentów; to narzędzia pomagające młodym ludziom w odnalezieniu swojej tożsamości ${ }^{55}$. Wraz z zaletami social media pojawiły się zjawiska negatywne. W sieci jest mnóstwo treści generowanych przez jej użytkowników, ale niewiele z nich wartych jest czytania, oglądania, słuchania, a co za tym idzie - również podążania za nimi ${ }^{56}$. $\mathrm{Z}$ drugiej strony im więcej treści generują sami użytkownicy social media, tym trudniej markom reagować na sytuacje kryzysowe. Internetowe sieci społeczne, w których mechanizmem

${ }^{51}$ R. Kaczmarek, W. Walczak, Social media: wczoraj, dziś, jutro, [w:] Social media 2010-20152020, https://nowymarketing.pl/fs/1,social-media-2010-2015-2020 (dostęp: 17.11.2018).

52 Reklama w Internecie. Raport Grudzień 2017, https://interaktywnie.com/.../raport-interaktywnie-com-reklama-w-internecie-2017-25 (dostęp: 18.11.2018).

${ }^{53}$ N. Ferguson, Cywilizacja zachodnia i reszta świata, przeł. P. Szymor, Kraków 2013.

${ }^{54}$ D. Bell, Kulturowe sprzeczności kapitalizmu, przeł. S. Amsterdamski, Warszawa 2014.

${ }^{55}$ Hashtag nation marketing to the selfie generation, https://download.havas.com/prosumerreports/hashtag-nation-marketing-to-the-selfie-generation/ (dostęp: 15.11.2018).

${ }^{56}$ D. Kim, Co dalej w społecznościach?, [w:] Social media 2010-2015-2020, https://nowymarketing.pl/fs/1,social-media-2010-2015-2020 (dostęp: 17.11.2018). 
stratyfikacji jest popularność oraz liczba subskrybentów i w których można skomentować obcych i bliskich, wystawiając się równocześnie na społeczną ocenę, może być odczuwana jako presja zarówno dla konsumentów, jak i marek.

\section{Bibliografia}

Aldridge A., Konsumpcja, przeł. M. Żakowski, Warszawa 2006.

Appadurai A., Nowoczesność bez granic. Kulturowe wymiary globalizacji, przeł. Z. Pucek, Kraków 2005.

Baumann Z., Konsumowanie życia, Kraków 2009.

Baumann Z., Praca, konsumpcjonizm i nowi ubodzy, Kraków 2006.

Lipovetsky G., L'Empire de l'éphémère: la mode et son destin dans les sociétés modernes, Princeton-Oxford 1994.

Bell D., Kulturowe sprzeczności kapitalizmu, przeł. S. Amsterdamski, Warszawa 2014.

Burszta W.J., Styl życia - kontrkultura - gadżet, [w:] Co nas łączy, co nas dzieli?, red. J. Mucha, E. Narkiewicz-Niedbalec, M. Zielińska, Zielona Góra 2008.

Castells M., Władza komunikacji, przeł. J. Jedliński, P. Tomanek, Warszawa 2013.

Cudowska A., Wspólnota w kulturze indywidualizmu, [w:] Wspólnoty z perspektywy edukacji międzykulturowej, red. J. Nikitorowicz, J. Muszyńska, M. Sobecki, Białystok 2009.

Ferguson N., Cywilizacja zachodnia i reszta świata, przeł. P. Szymor, Kraków 2013.

Giddens A., Nowoczesność i tożsamość. „Ja” i społeczeństwo w epoce późnej nowoczesności, przeł. A. Szulżycka, Warszawa 2002.

Halawa M., Facebook - platforma algorytmicznej towarzyskości i technologia siebie, „Kultura i Społeczeństwo" 2013, nr 4, doi:10.2478/kultura-2014-0007.

Halawa M., Życie codzienne z telewizorem. Z badań terenowych, Warszawa 2006.

Heath J., Potter A., Nation of Rebel. Why Counterculture Became Consumer Culture, New York 2004. Iwasiński Ł., Konsumpcja jako budowanie tożsamości, „Studia Socjologiczne” 2015, nr 4 (219).

Iwasiński Ł., Społeczeństwo konsumpcyjne w ujęciu Zygmunta Baumana, „Kultura i Społeczeństwo” 2015, nr 4.

Jacyno M., Kultura indywidualizmu, Warszawa 2007.

Kaufmann, J.C., Kiedy ja jest innym. Dlaczego i jak coś się w nas zmienia, przeł. A. Kapciak, Warszawa 2013.

Kenneth G., Nasycone Ja. Dylematy tożsamości w życiu współczesnym, przeł. M. Marody, Warszawa 2009.

Krajewski M., Przeterminowanie, [w:] Młodzi i media nowe media a uczestnictwo w kulturze. Raport Centrum Badań nad Kulturą Popularna SWPS, Warszawa 2010.

Kurasiński A., Raport media społecznościowe, https://blog.kurasinski.com/2010/03/raport-mediaspolecznosciowe/.

Lash S., Lury C., Global Culture Industry: The Mediation of Things, Cambridge 2007.

McKendrick N, Brewer J., Plumb J.H, The Birth of a Consumer Society: The Commercialization of Eighteenth-Century England, Bloomington 1982.

Pasikowski K., Konsumpcja: w pogoni za wolnością?, [w:] Co nas wyzwala, co nas zniewala? Młodzi o wolności, red. A. Kampka, K. Masłowska A. Pawłowska, Warszawa 2018.

Ostruszka Ł., Technologia napędza wartość marki, https://www.pb.pl/technologia-napedza-watoscmarki-931535.

Raport Wave, Znaczenie momentów, http://www.universalmccann.pl/news/68/114/Wave-9-Polakzapatrzony-w-Facebooka.

Reklama w Internecie. Raport Grudzień 2017, https://interaktywnie.com/biznes/newsy/biznes/ raport-interaktywnie-com-reklama-w-internecie-2017-256638 
Romaniszyn K., O sile konsumpcjonizmu, [w:] Nowa droga do zniewolenia? O życiu w społeczeństwie konsumpcyjnym, red. K. Romaniszyn, Kraków 2011.

Smith A., Anderson M., A majority of Americans use Facebook and YouTube, but young adults are especially heavy users of Snapchat and Instagram, http://www.pewinternet.org/2018/03/01/social-media-use-in-2018/.

Social media 2010-2015-2020, https://nowymarketing.pl/fs/1,social-media-2010-2015-2020.

Staniszewski M., Narzędzia: zarządzanie znaczeniem marki, „Marketing w Praktyce” 2008, nr 8, http://marketing.org.pl/archiwum/index.php/go=2/act=2/aid=m4895cf888d7cf.

Szlendak T., Pietrowicz K., Moda, wolność i kultura konsumpcji, [w:] Rozkoszna zaraza. O rządach mody i kulturze konsumpcji, red. T. Szlendak, K. Piotrowicz, Wrocław 2007.

Szymanek A., Branża mody a trendy w mediach społecznościowych, http://fashionweare.com/rynek_ mody/bran\%C5\%BCa-mody-a-trendy-w-mediach-spo\%C5\%82eczno\%C5\%9Bciowych-373.

Thompson J.B., Media i nowoczesność: społeczna teoria mediów, przeł. I. Mielnik, Wrocław 2001.

Wilkinson R., Pickett K., Duch równości. Tam gdzie panuje równość, wszystkim żyje się lepiej, przeł. P. Listwan, Warszawa 2011.

Wolska- Zogata I., Prasa informacyjna w ekosystemie nowych mediów, „Media - Kultura Komunikacja Społeczna" 2018, nr 14/3.

Zalewska J., Rewolucja konsumpcyjna: od gospodarki naturalnej do społeczeństwa mody, [w:] Krótkie wykłady $z$ socjologii. Kategorie, problemy, subdyscypliny, red. E. Tarkowska, A. Firkowska-Mankiewicz, T. Kanasz, Warszawa 2013.

Zalewska J., Wplyw mody na kształtowanie się emocjonalnego podmiotu, [w:] Od obyczaju do mody: Przemiany życia codziennego, red. J. Zalewska, M. Cobel-Tokarska, Warszawa 2014.

\section{Social media and new marketing within the consumer society}

\section{Summary}

In sociological theories, one can find at least two explanations for the emergence of a consumer society. One of them refers to economics, looking to the growth of production efficiency and the enrichment of society as the causes of consumption revolution. The second refers to culture, treating the change in social practices, consumption patterns as a result of changes in the usual social norms. The paradigm that has dominated for over 10 years in the social sciences sees in consumption the tool of reflective shaping of the consumer's identity. On the other hand, some sociologists look for units of identity formatted by marketing. Undoubtedly, the author is closer to this second statement, but he sees a kind of technological determinism. The contemporary consumer, immersed in the world of new technologies, which is his choice, at the same time submits to marketing technical means, made possible by these technologies. The author, based on the existing data, puts forward the thesis that individualism, strengthened among others by new media, has been successfully used by marketers to sell standardized products. 